OPEN ACCESS

Edited by:

Tengfei Zhou,

University of Wollongong, Australia

Reviewed by:

Ye Liu,

South-Central University for

Nationalities, China

Li Shuang,

China Three Gorges University, China

*Correspondence:

Xuezhong Gong

xzgong@qdu.edu.cn

Youwen Liu

ywliu@hust.edu.cn

Specialty section:

This article was submitted to

Nanoscience,

a section of the journal

Frontiers in Chemistry

Received: 04 March 2020

Accepted: 14 April 2020

Published: 15 May 2020

Citation:

Guan $M$, Wang $Q$, Zhang X, Bao J,

Gong $X$ and Liu $Y$ (2020)

Two-Dimensional Transition Metal

Oxide and Hydroxide-Based

Hierarchical Architectures for

Advanced Supercapacitor Materials.

Front. Chem. 8:390.

doi: 10.3389/fchem.2020.00390

\section{Two-Dimensional Transition Metal Oxide and Hydroxide-Based Hierarchical Architectures for Advanced Supercapacitor Materials}

\author{
Meili Guan ${ }^{1}$, Qiuwan Wang ${ }^{1}$, Xuan Zhang ${ }^{1}$, Jian Bao ${ }^{1}$, Xuezhong Gong ${ }^{2 *}$ and Youwen Liu ${ }^{3 *}$ \\ ${ }^{1}$ Institute for Energy Research, School of Chemistry and Chemical Engineering, Jiangsu University, Zhenjiang, China, \\ ${ }^{2}$ National Center of International Joint Research for Hybrid Materials Technology, National Base of International Science and \\ Technology Cooperation on Hybrid Materials, College of Materials Science and Engineering, Institute of Hybrid Materials, \\ Qingdao University, Qingdao, China, ${ }^{3}$ State Key Laboratory of Material Processing and Die \& Mould Technology, School of \\ Materials Science and Engineering, Huazhong University of Science and Technology, Wuhan, China
}

The supercapacitor has been widely seen as one of the most promising emerging energy storage devices, by which electricity is converted from chemical energy and stored. Two-dimensional (2D) metal oxides/hydroxides (TMOs/TMHs) are revolutionizing the design of high-performance supercapacitors because of their high theoretical specific capacitance, abundance of electrochemically active sites, and feasibility for assembly in hierarchical structures by integrating with graphitic carbon, conductive polymers, and so on. The hierarchical structures achieved can not only overcome the limitations of using a single material but also bring new breakthroughs in performance. In this article, the research progress on 2D TMOs/TMHs and their use in hierarchical structures as supercapacitor materials are reviewed, including the evolution of supercapacitor materials, the configurations of hierarchical structures, the electrical properties regulated, and the existence of advantages and drawbacks. Finally, a perspective covering directions and challenges related to the development of supercapacitor materials is provided.

\footnotetext{
Keywords: two-dimensional nanosheets, transition metal oxide and hydroxide, hierarchical structure, integration, supercapacitor
}

\section{INTRODUCTION}

Global warming and the rapid depletion of fossil fuels are driving the development of sustainable and renewable energy. At present, the renewable energy sources of wind, tidal, geothermal, and solar energy have been researched and utilized (Yuksel and Ozturk, 2017; Cranmer et al., 2018; Mo et al., 2018; Song et al., 2018). However, these energy sources are highly dependent on nature, which is variable and unpredictable. Hence, an energy storage system is essential for efficiently collecting this natural energy, and, meanwhile, allows the energy to be rapidly exported in the form of stable electric energy. In recent years, the supercapacitor is becoming popular as a kind of energy storage device that is not only efficient and practical but also convenient and environmental friendly (Lukatskaya et al., 2016; Salanne et al., 2016; Wang et al., 2017).

The supercapacitor is also known as a Faraday quasi capacitor or electrochemical capacitor. It stores charges through a reversible redox reaction at the interface between electrode materials 
and electrolyte, unlike a traditional capacitor, it offers higher specific capacity and energy density (Simon and Gogotsi, 2010; Kate et al., 2018). Compared with a secondary battery, the supercapacitor possesses overwhelming advantages in terms of a shorter charging time and a long cycle life and, higher power density (Staaf et al., 2014; Zhao and Sun, 2018). Therefore, the supercapacitor is a kind of energy storage device that is intermediate between a traditional capacitor and a secondary battery that can be regarded as a complementary device between a battery and a traditional capacitor and can meet the needs of human beings for new energy.

The structural configuration of a supercapacitor mainly consists of electrode material, a diaphragm, electrolyte, and collecting fluid (Muzaffar et al., 2019). The energy storage is mainly from the charge transfer process at the interface of electrode and electrolyte, so the electrode material is the key factor in the performance of the supercapacitor. At present, there are three prevailing types of electrode materials under research, namely carbon materials [e.g., graphene (Liu et al., 2010), carbon nanotubes (Shang et al., 2015), activated carbon (Gamby et al., 2001; Jin et al., 2016), and porous carbon (Bu et al., 2017)], conducting polymer materials [e.g., polyaniline (PANI) (Lim et al., 2015; Lyu et al., 2019), polypyrrole (PPy) (Huang et al., 2015), polythiophene (PTh) (Ambade et al., 2017), and poly (3, 4-ethylenedioxythiophene) (PEDOT) (Liu et al., 2008)], and TMOs/TMHs $\left[\mathrm{RuO}_{2}\right.$ (Sugimoto et al., 2003), $\mathrm{MnO}_{2}$ (Song et al., 2010; Zhao et al., 2012; Huang et al., 2018), $\mathrm{MoO}_{3}$ (Brezesinski et al., 2010; Hanlon et al., 2014), $\mathrm{Nb}_{2} \mathrm{O}_{5}$ (Augustyn et al., 2013), $\mathrm{V}_{2} \mathrm{O}_{5}$ (Qi et al., 2018), $\mathrm{Ni}(\mathrm{OH})_{2}$ (Ida et al., 2008; Fu et al., 2014), and $\mathrm{Co}(\mathrm{OH})_{2}$ (Ji et al., 2012; Gao et al., 2014)]. In particular, carbon material is the most widely used electrode material due to its diversity and abundance as a resource. The capacitance over a carbon-based supercapacitor electrode is achieved through pure electrosorption of the electrical double-layer; thus, the structure of the electrode material will not collapse with the insertion and withdrawn of electrolyte ions during the charging and discharging processes. This leads to superior cycle stability, extending to tens of thousands or even hundreds of thousands of cycles (Frackowiak and Beguin, 2001; Liu et al., 2014). However, the energy density of carbon-based supercapacitors is low due to the storage mechanism, which rarely meets the needs of practical application. In contrast, conducting polymer electrode materials achieve high charge density by a reversible redox reaction of elements doping/dedoping, thus realizing large electric energy storage (Snook et al., 2011). However, the conducting polymer skeleton is prone to expanding and shrinking in the chargingdischarging process, leading to low cycle stability (González et al., 2016). In addition, most of the conducting polymer materials are dense structures with limited interfaces, which restricts the amount of electrode material that is able to fully contact with the electrolyte and results in relatively low power density.

It is noteworthy that TMOs/TMHs exhibit potential for the fabrication of supercapacitor electrodes due to their high theoretic capacity and ultrahigh power density (Yuan et al., 2014; Wang et al., 2015; Zhang H. et al., 2015; Nguyen and Montemor, 2019). The energy storage can be achieved by either electrosorption or reversible redox reactions (Lee et al.,
2010). Normally the valance state would change accompany with the charging-discharging process. Hence, for comparison, TMOs/TMHs have exhibited higher powder density and stability than traditional carbon and conducting polymer materials. Although problems arise from their narrow working voltage window, low conductivity, and small reaction area, these can be solved by structural engineering and composition, such as by controlling dimensionality and morphology (Zhu et al., 2014; Najafpour et al., 2015; Xu et al., 2015; Yue and Liang, 2015; Yu et al., 2015).

In this review, we summarize the recent progress in $2 \mathrm{D}$ TMOs/TMHs as supercapacitor electrode material. Further, 2D transition metal oxide/hydroxide-based hierarchical structures are covered. The different technical strategies in design and synthesis for optimizing the conductivity, structural stability, surface physical, and chemical properties, and structural morphology of the hierarchical composites are also detailed. A supercapacitor electrode with high specific capacitance, good rate capability, and excellent cycle stability can be obtained by tuning the electrochemical properties of the electrode materials. Finally, a perspective covering directions and challenges related to the development of supercapacitor materials is provided.

\section{TWO-DIMENSIONAL TRANSITION METAL OXIDES/HYDROXIDES}

Transition metal oxides/hydroxides (TMOs/TMHs) are the most representative active electrochemical pseudocapacitor materials and are widely known for their high theoretical capacitance, abundance in nature, and high energy density (Jiang et al., 2012). However, poor intrinsic conductivity and other shortcomings have limited their performance as supercapacitor materials. Hence, 2D ultrathin TMOs/TMHs have been widely studied and applied in supercapacitors due to their advantages of high specific surface area and improved planar electronic conductivity (Gao et al., 2014; Liu W. et al., 2017; Zhu et al., 2018). Most importantly, the atomic thickness shortens the ion diffusion path and reduces ion diffusion resistance.

So far, there are two main strategies, that is, "top-down" and "bottom-up" methods, for obtaining 2D TMOs/TMHs (Sun et al., 2017; Mei et al., 2018), as shown in Table 1. “Top-down” mainly refers to the chemical or mechanical exfoliation of layered bulk materials, such as by mechanical exfoliation and liquid-phase exfoliation (Coleman et al., 2011; Rui et al., 2013; Zhang Y. Z. et al., 2015; Peng et al., 2017; Zavabeti et al., 2017; Tao et al., 2019). It is reported that $\mathrm{MoO}_{3}, \mathrm{MnO}_{2}$, and $\mathrm{RuO}_{2}$ nanosheets, etc., can be made at a large scale by ultrasonic exfoliation in ethanol/water and can be applied to solid-state symmetrical supercapacitors (Dutta et al., 2019). A liquid-phase exfoliation method with the aid of lithium (Li) intercalation and deintercalation was developed for the preparation of quasi-layered $\mathrm{VO}_{2}$ ultrathin nanosheet (Liu et al., 2012). The underlying mechanism is the insertion of $\mathrm{Li}$ ions to break the chemical bonds of the layers. Subsequent replacement of Li ions by larger molecules and ultrasonic treatment can result in a dispersed $\mathrm{VO}_{2}$ ultrathin nanosheet. The "bottom-up" synthetic protocol 
TABLE 1 | Summary and comparison between top-down and bottom-up strategies for the fabrication of 2D TMOs/TMHs and their pros and cons.

\begin{tabular}{|c|c|c|c|c|}
\hline Strategy & Method & 2D TMOs/TMHs & References & Pros and cons \\
\hline \multirow[t]{7}{*}{ Top-down } & Mechanical cleavage & $\mathrm{MnO}_{2}$ & $\begin{array}{l}\text { Peng et al., 2017; Dutta } \\
\text { et al., } 2019\end{array}$ & $\begin{array}{l}\text { Easy operation; } \\
\text { Only applicable for layered structure materials }\end{array}$ \\
\hline & & $\mathrm{MoO}_{3}$ & Dutta et al., 2019 & \\
\hline & & $\mathrm{RuO}_{2}$ & Dutta et al., 2019 & \\
\hline & & $\mathrm{Ti}_{5} \mathrm{NbO}_{14}$ & Zhang et al., 2010 & \\
\hline & Liquid-phase exfoliation & $\mathrm{V}_{2} \mathrm{O}_{5}$ & Rui et al., 2013 & \\
\hline & & $\mathrm{VO}_{2}$ & Liu et al., 2012 & \\
\hline & & $\mathrm{MoO}_{3}$ & Zhang Y. Z. et al., 2015 & \\
\hline \multirow[t]{13}{*}{ Bottom-up } & Self-assembly & $\mathrm{TiO}_{2}$ & Sun J. et al., 2014 & \multirow{13}{*}{$\begin{array}{l}\text { Applicable for both layered and non-layered } \\
\text { structure materials; } \\
\text { Can be produced at large scale; } \\
\text { Harsh synthetic conditions; } \\
\text { Difficult to obtain high-quality 2D crystals. }\end{array}$} \\
\hline & & $\mathrm{ZnO}$ & Sun et al., 2017 & \\
\hline & & $\mathrm{Co}_{3} \mathrm{O}_{4}$ & Hu et al., 2017 & \\
\hline & & $\mathrm{WO}_{3}$ & Sun J. et al., 2014 & \\
\hline & Chemical vapor deposition & $\mathrm{TiO}_{2}$ & Lee and Sung, 2012 & \\
\hline & & $\mathrm{WO}_{3}$ & Liu et al., 2015 & \\
\hline & Directional connection & $\mathrm{SnO}_{2}$ & Wang C. et al., 2012 & \\
\hline & & $\mathrm{CeO}_{2}$ & Yu et al., 2010 & \\
\hline & & $\mathrm{Co}(\mathrm{OH})_{2}$ & Gao et al., 2014 & \\
\hline & Topological chemical & $\mathrm{WO}_{3}$ & Liu et al., 2016 & \\
\hline & transformation & $\mathrm{Nb}_{2} \mathrm{O}_{5}$ & Wen et al., 2017 & \\
\hline & & $\mathrm{ZnCo}_{2} \mathrm{O}_{4}$ & Bao et al., 2018 & \\
\hline & & Cobalt nickel oxide & Yang et al., 2019 & \\
\hline
\end{tabular}

starts from appropriate design at the atomic or molecular level by the aid of technologies, such as self-assembly (Sun J. et al., 2014; Hu et al., 2017; Sun et al., 2017), chemical vapor deposition (Lee and Sung, 2012; Liu et al., 2015), directional connection, and topological chemical transformation of layered intermediates (Liu et al., 2016; Wen et al., 2017; Bao et al., 2018), to synthesize a 2D nanostructure. For instance, five atomic layer thickness $\mathrm{Co}(\mathrm{OH})_{2}$ ultrathin nanosheet was synthesized by the orientation connection method and was assembled into an asymmetric vertical all-solid-state flexible supercapacitor with excellent specific capacitance and cycle stability (Gao et al., 2014). For non-layered 2D materials, Qiu and Zheng, for the first time, successfully observed the in-situ transformation of metal oxides from $3 \mathrm{D}$ nanoparticles as intermediate products to $2 \mathrm{D}$ oxide nanoflakes by LBNL's in-situ liquid-phase transmission electron microscopy technology, revealing the new evolution strategy of $3 \mathrm{D}$ to $2 \mathrm{D}$ materials at the atomic level, and also paving the way to obtaining ultrathin nanostructures from non-layered materials (Yang et al., 2019).

\section{D TMOs/TMHs-BASED HIERARCHICAL ENGINEERING FOR SUPERCAPACITOR MATERIALS}

Although great efforts have been put into the development of 2D TMOs/TMHs for supercapacitor electrodes, challenges still exist when using a single electrode material. The drawback lies in low actual capacitance, limited improvement of energy density, and the poor rate capability caused by low conductivity, which have restricted the performance of such supercapacitors in practical applications (Jiang et al., 2012; Mahmood et al., 2019). In order to overcome the limitations of single electrode materials, it is necessary to combine 2D TMOs/TMHs with other low-dimensional nanomaterials to construct hierarchical nanostructures, which can not only optimize the configuration to overcome the agglomeration of $2 \mathrm{D}$ nanosheets but also complement and enhance the performance of different electrode materials so as to realize effective improvement of the performance for the supercapacitor device (Figure 1).

\section{TMOs/TMHs HIERARCHICAL STRUCTURES}

The engineering of hierarchical structures by hybridizing different TMOs/TMHs is regarded as an efficient strategy to combine the advantages of different materials (Wu et al., 2013; Dinh et al., 2014; Zheng et al., 2016, 2018; Ouyang et al., 2019). The function of this kind of hierarchical structure can be generally summarized as overcoming the drawbacks of the individual components and preventing agglomeration of nanosheets. Thus, capacitance performance is predominantly enhanced because of the expected synergistic effect. Hierarchical structures with different morphologies can be formed through self-assembly (Huang et al., 2014; Feng et al., 2018), layer stacking (Zhu et al., 2012), and heterostructure core-shell engineering ( $\mathrm{Li}$ et al., 2014; Sun Z. et al., 2014; Ho and Lin, 2019), which also have significant effects on the energy density and stability of the supercapacitors.

A $3 \mathrm{D} \mathrm{V}_{2} \mathrm{O}_{5}$ architecture was constructed by using ultrathin $\mathrm{V}_{2} \mathrm{O}_{5}$ nanosheets as building blocks with a thickness of $4 \mathrm{~nm}$ via a freeze-drying process (Zhu et al., 2013). Due to the benefits of 




FIGURE 1 | Schematic illustration of the use of TMOs/TMHs nanosheets to form 2D TMOs/TMHs-based hierarchical structures for a supercapacitor with expected performance promotion.

its porous and ultrathin nature, as well as the $3 \mathrm{D}$ interpenetrating structure, a high surface area and shortened diffusion length were expected, thus enabling such a supercapacitor electrode to exhibit high capacitance, high energy density, and excellent stability (Figures 2A-C). A flexible film-like supercapacitor was fabricated via a vacuum filtration method by integrating $\mathrm{MnO}_{2}$ and $\mathrm{Ti}_{3} \mathrm{C}_{2}$ nanoflakes as the electrode, as shown in Figure 2D (Liu Y. et al., 2017). With the aid of good solubility, similar twodimensional geometry, the high theoretical capacity of $\mathrm{MnO}_{2}$, and the good conductivity of $\mathrm{Ti}_{3} \mathrm{C}_{2}$, the composite electrode exhibited good capacitance performance with a high massspecific capacitance of $305 \mathrm{~F} / \mathrm{g}$ at a current density of $1 \mathrm{~A} / \mathrm{g}$. The fabricated symmetrical flexible supercapacitor device exhibited a maximum energy density of $8.3 \mathrm{Wh} / \mathrm{kg}$, and the power density could reach 2,376 W/kg (Figures 2E,F). Characterizations and deeper understanding of the interaction between the stacked hierarchical structure and electrochemical performance revealed that the layered stacking structure is more conducive to improve the electrochemical performance of the electrode compared with traditional capacitors.

Forming a heterostructure or core-shell structures has been adopted as an efficient strategy for offering a large surface area for more Faradaic reaction sites and high conductivity to accelerate the charge transfer and therefore to improve the electrochemical performances of nanocomposites. For instance, a $\mathrm{ZnCo}_{2} \mathrm{O}_{4}-\mathrm{MnO}_{2}$ heterostructure on $\mathrm{Ni}$ foam was shown to be an active electrode material with a porous nanostructure, providing a considerably large electroactive area, and exhibited ideal capacitive behavior, with a maximum Cs of 2,057 F/g at a current density of $1 \mathrm{~A} / \mathrm{g}$ and cycling stability of $96.5 \%$ after 5,000 cycles (Kumbhar and Kim, 2018) (Figures 2G-I). Unique core-shell arrays of $\mathrm{CoFe}_{2} \mathrm{O}_{4} @ \mathrm{MnO}_{2}$ on nickel foam were also studied as an electrode material for a supercapacitor. Compared to the individual $\mathrm{CoFe}_{2} \mathrm{O}_{4}$ and $\mathrm{MnO}_{2}$ nanosheets, the composite electrode exhibited much higher specific area capacitance of $3.59 \mathrm{~F} / \mathrm{cm}^{2}(\approx 1,995 \mathrm{~F} / \mathrm{g})$ at a current density of $2 \mathrm{~mA} / \mathrm{cm}^{2}$ and a smaller semicircle in EIS, indicating faster ion insertion/extraction during electrochemical reactions, which can all be attributed to the hierarchical core-shell nanostructure. The asymmetric supercapacitor assembled using a $\mathrm{CoFe}_{2} \mathrm{O}_{4} @ \mathrm{MnO}_{2}$ electrode had maximum energy density and maximum power density of $37 \mathrm{Wh} / \mathrm{kg}$ and $4,800 \mathrm{~W} / \mathrm{kg}$, respectively, with long-term cycling stability ( $91.4 \%$ retention after 2,250 cycles) (Gao et al., 2017).

Besides, mixed dimensional hierarchical structures have also been reported. For instance, a hybrid of $\mathrm{NiCo}_{2} \mathrm{O}_{4}-\mathrm{MoS}_{2}$ consisting of $2 \mathrm{D} \mathrm{NiCo} \mathrm{O}_{4}$ nanosheets and $1 \mathrm{D} \mathrm{MoS}_{2}$ nanowires were grown on a $3 \mathrm{D} \mathrm{Ni}$ foam network, forming mixeddimensional hierarchical structures, as shown in Figures 3A-C. During the growth process, $\mathrm{NiCo}_{2} \mathrm{O}_{4}$ nanosheets intertwined on the Ni surface, providing sites for $\mathrm{MoS}_{2}$ nanowires, while a higher concentration of $\mathrm{S}^{2-}$ lead to thinner nanowires. These features enable a high specific surface area and a shortened diffusion path for ions and electrons, which lead to the enhancement of the electron/ion transfer rate in the electrodes (Wen et al., 2018). The assembled supercapacitor device delivered a maximum energy density of $18.4 \mathrm{Wh} / \mathrm{kg}$ and a power density of $1200.2 \mathrm{~W} / \mathrm{kg}$ with excellent stability (specific capacitance retention of $98.2 \%$ after 8,000 cycles) (Figures 3D,E).

\section{TMOs/TMHs/CARBON-BASED HIERARCHICAL STRUCTURES}

Graphene, described as the "famous star" among carbon materials (Gong et al., 2016), it is an excellent two-dimensional scaffold upon which to construct composite materials with 2D TMOs/TMHs because its large surface area and the huge amount of cross-linking of the conjugated $\pi$-bond structure endow it with superior conductivity (in-plane carrier mobility up to $200,000 \mathrm{~cm}^{2} \mathrm{v}^{-1} \mathrm{~s}^{-1}$ ) and physical structure stability (high mechanical strength and flexibility) (Novoselov et al., 2012). The electronic conduction and mechanical stability of the hierarchical structure formed are improved by the synergistic effect of the two components (Stankovich et al., 2006). Hence, a supercapacitor with excellent performance is expected due to the improved electrochemical reaction rate and cycle stability.

At present, a large amount of progress has been made in the preparation of high-performance energy storage materials by combining TMOs/TMHs with graphene. The application 


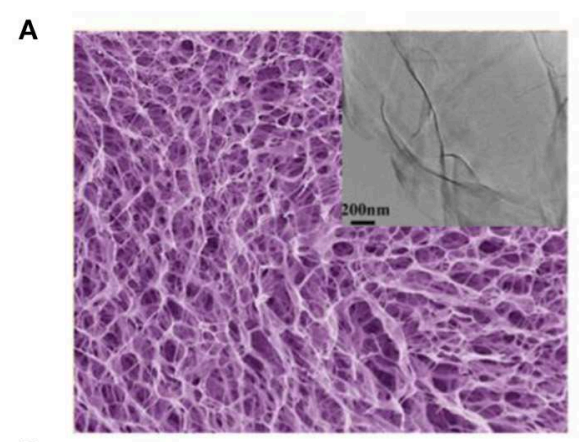

D

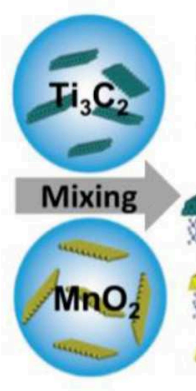

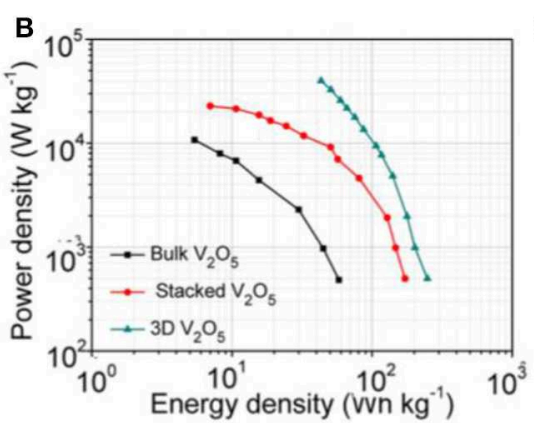

E

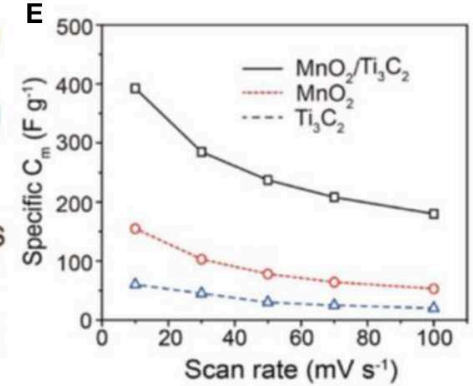

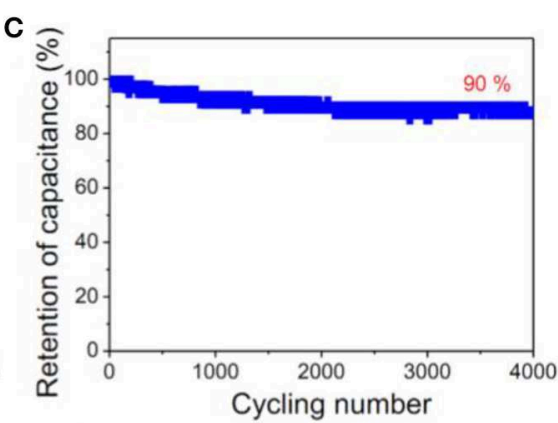

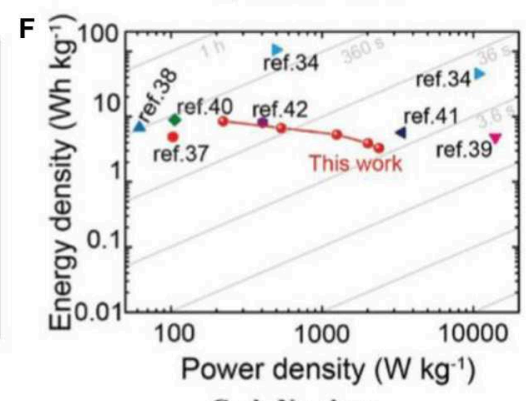

G

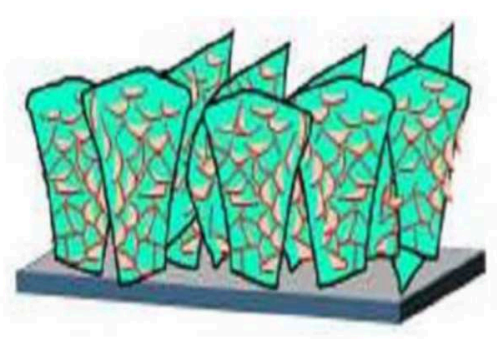

$\mathrm{ZnCo}_{2} \mathrm{O}_{4}$

$\mathrm{MnO}_{2}$
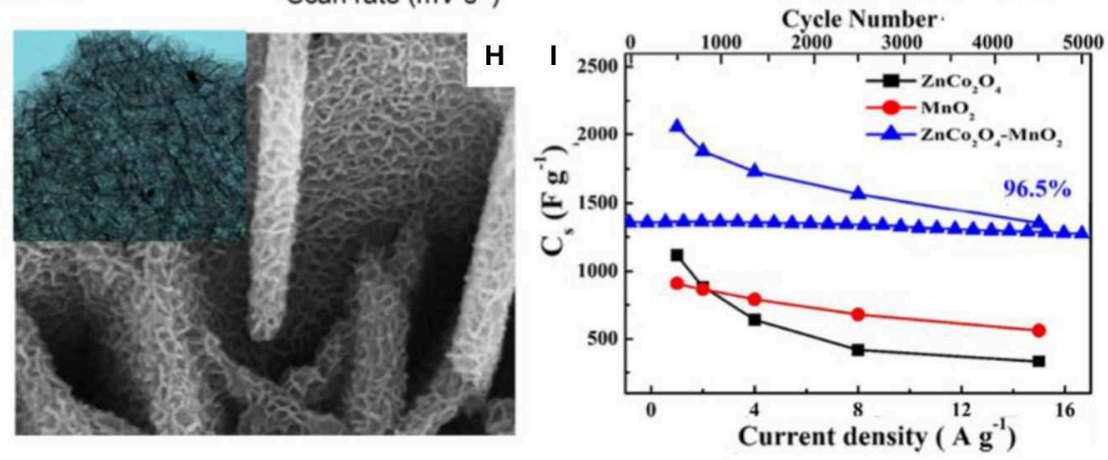

FIGURE 2 | (A) FESEM images of the 3D V $\mathrm{O}_{5}$ architecture constructed from nanosheets (inset: TEM image of a nanosheet). (B) Power density and energy density of three electrodes. (C) Cycling performance of the $3 \mathrm{D} \mathrm{V}_{2} \mathrm{O}_{5}$ architecture (Zhu et al., 2013). (D) Schematic drawing of the fabrication of the $\mathrm{MnO}_{2} / \mathrm{Ti}_{3} \mathrm{C}_{2}$ hybrid film, with molecular sheets stacked in a randomly interstratified manner. (E) Rate capability of the hybrid $\mathrm{MnO}_{2} / \mathrm{Ti}_{3} \mathrm{C}_{2}$ electrode compared with neat $\mathrm{MnO}_{2}$ and $\mathrm{Ti}_{3} \mathrm{C}_{2}$

electrodes. (F) Performance comparison of the $\mathrm{MnO}_{2} / \mathrm{Ti}_{3} \mathrm{C}_{2}$ hybrid with other reported materials on a Ragone plot (Liu W. et al., 2017). (G) Schematic of the coating of $\mathrm{ZnCo}_{2} \mathrm{O}_{4}$ nanoflakes with $\mathrm{MnO}_{2}$ nanosheets. (H) FESEM images and (inset) TEM images of $\mathrm{ZnCo}_{2} \mathrm{O}_{4}$ nanoflakes coated with $\mathrm{MnO}_{2}$ nanosheets. (I) Variation in $\mathrm{C}_{s}$ with respect to current density and cycling performance at $15 \mathrm{~A} / \mathrm{g}$ for electrodes (Gao et al., 2017).

of pseudocapacitive $\mathrm{V}_{2} \mathrm{O}_{5}$ nanosheets and graphene in allsolid-state flexible thin-film supercapacitors (ASSTFSs) has been reported (Bao et al., 2014). By rationally integrating the two components, electron transfer was accelerated, and diffusion paths were shortened, leading to strong electrochemical performance, with a capacitance of $11,718 \mu \mathrm{F} / \mathrm{cm}^{2}$ at $0.2 \mathrm{~A} / \mathrm{m}^{2}$, an energy density of $1.13 \mu \mathrm{W} \mathrm{h} / \mathrm{cm}^{2}$ at a power density of $10.0 \mu \mathrm{W} / \mathrm{cm}^{2}$, and excellent long-term cycling stability for 2,000 charge-discharge cycles (Figure 4). The superior electrochemical performance thoroughly demonstrated the merit of a hierarchical architecture combining pseudocapacitive $\mathrm{V}_{2} \mathrm{O}_{5}$ nanosheets and graphene.

The Xie, group for the first time, fabricated a flexible allsolid-state thin-film pseudocapacitor using $\beta-\mathrm{Ni}(\mathrm{OH})_{2}$ /graphene hybrid nanosheets as electrode materials via a layer-by-layer method (Xie et al., 2013). The assembly process of the
$\beta-\mathrm{Ni}(\mathrm{OH})_{2}$ /graphene hybrid includes electrostatic interaction between $\mathrm{GO}$ and $\mathrm{Ni}^{2+}$, interlayer $\mathrm{Ni}^{2+}$ diffusion, and confined $(\mathrm{NiOH})_{2}$ crystallization, as well as simultaneous reduction of graphene (Figures 5A-E). The combination of highly conductive graphene and pseudocapacitive $\beta-\mathrm{Ni}(\mathrm{OH})_{2}$ guarantees high specific capacitance and excellent stability for this novel energy storage material. The fabricated all-solid-state thin-film pseudocapacitor exhibits a high volumetric specific capacitance of $660.8 \mathrm{~F} / \mathrm{cm}$ and good cycling ability, as well as excellent flexibility with negligible degradation after 200 bending cycles (Figures 5F,G). Meanwhile, the ultrathin configuration of the hybrid nanosheets endows superior mechanical properties for the as-fabricated device, which can be regarded as a feasible energy supply for the exploitation of flexible electronics.

Following the all-solid-state planar configuration, the Xie group developed a quasi-2D ultrathin $\mathrm{MnO}_{2}$ /graphene hybrid for 


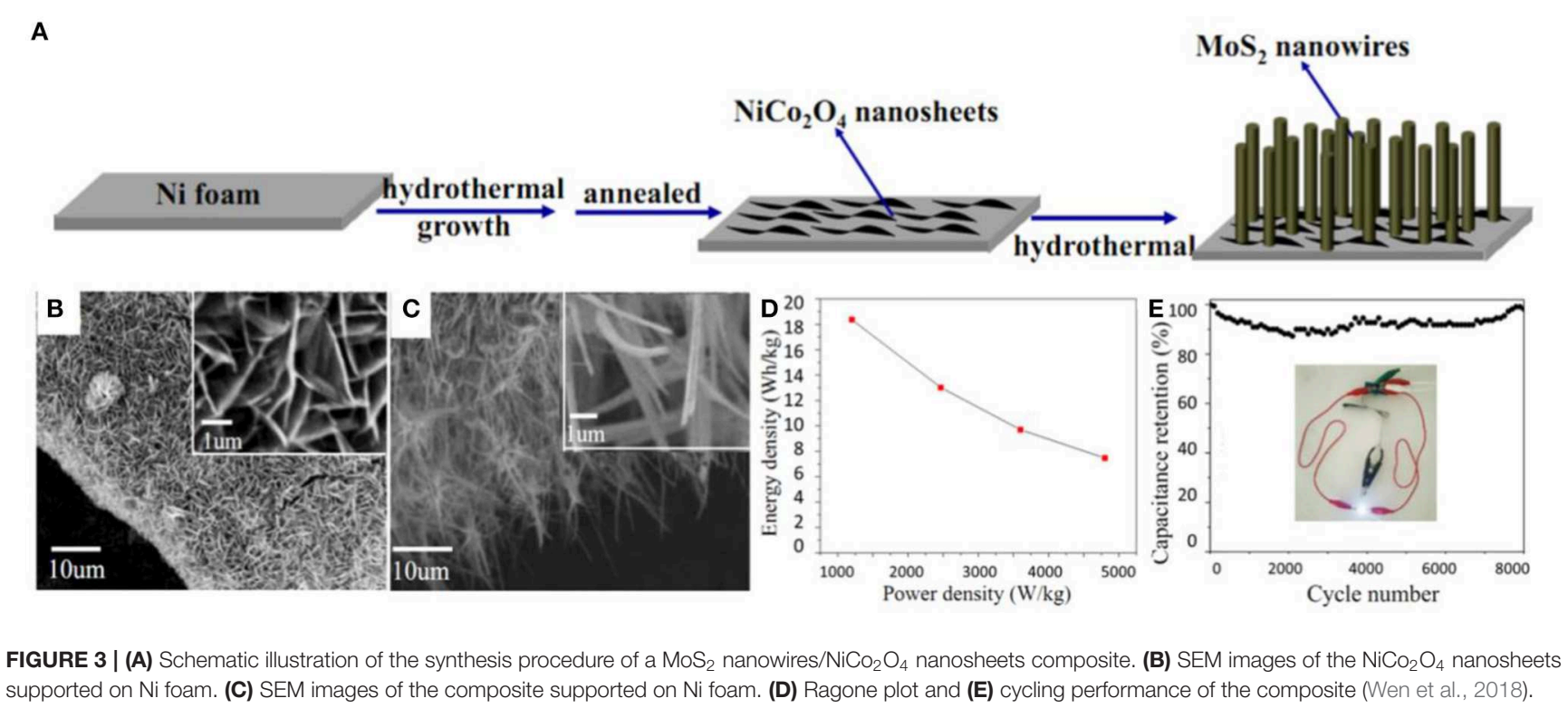

supported on Ni foam. (C) SEM images of the composite supported on Ni foam. (D) Ragone plot and (E) cycling performance of the composite (Wen et al., 2018).


FIGURE 4 | (A) Schematic illustration of the flexible ASSTFS. (B) SEM images of the as-obtained $\mathrm{V}_{2} \mathrm{O}_{5}$ nanosheet/graphene nanocomposite. (C) The first four cycles of a galvanostatic charge-discharge curve of the as-fabricated ASSTFS at a current density of $2.5 \mathrm{~A} / \mathrm{m}^{2}$. (D) Long-term cycling stability investigation of the ASSTFS after repeated bending/extension for 500 cycles (Bao et al., 2014).

fabricating a novel and high-performance planar supercapacitor (Peng et al., 2013). To make the best of the designed planar structure, a vacuum filtration method is adopted to produce films with controllable thickness and transferability. These hybrid 2D $\delta-\mathrm{MnO}_{2} /$ graphene thin films can be transferred onto a range of substrates such as PET, quartz, glass, and silicon wafer. By filling with a gel electrolyte of $\mathrm{PVA} / \mathrm{H}_{3} \mathrm{PO}_{4}$, an all-solid-state planar supercapacitor is fabricated (Figures 6A,B). Owing to the planar peculiarity of both graphene and $\delta-\mathrm{MnO}_{2}$ nanosheets, more electrochemically active surfaces for absorption/desorption of electrolyte ions were introduced, and charge transport was accelerated at the hybridized interlayer during the charging and discharging processes (Figures 6C-E). The device exhibited high specific capacitances of $267 \mathrm{~F} / \mathrm{g}$ at a current density of $0.2 \mathrm{~A} / \mathrm{g}$ and $208 \mathrm{~F} / \mathrm{g}$ at $10 \mathrm{~A} / \mathrm{g}$ and excellent rate capability and cycling stability (capacitance retention of $92 \%$ after 7,000 cycles) (Figures 6F,G). 


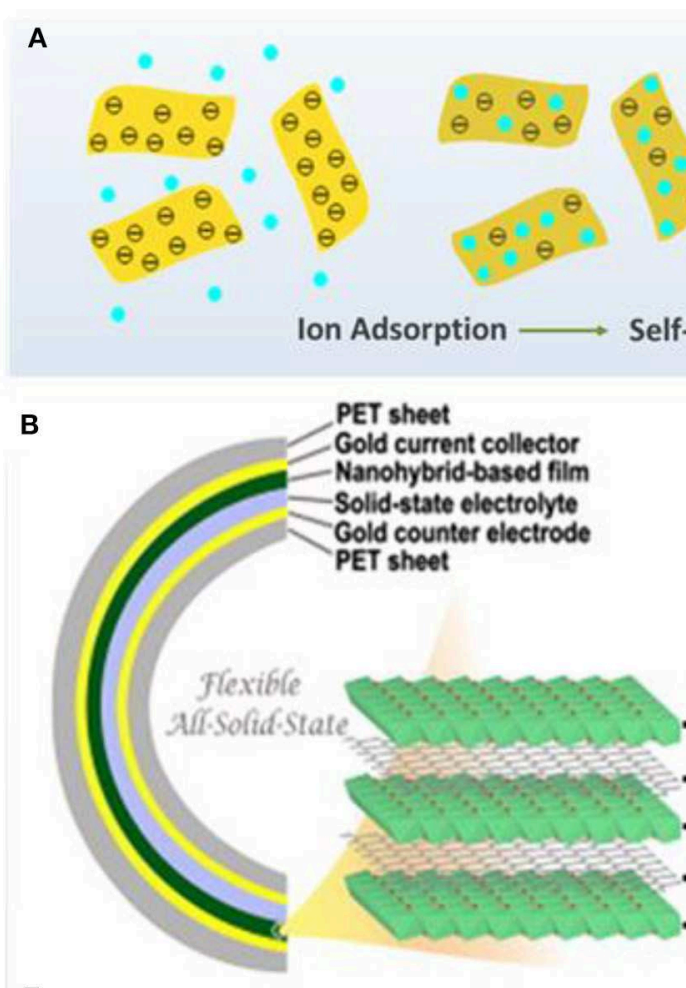

F



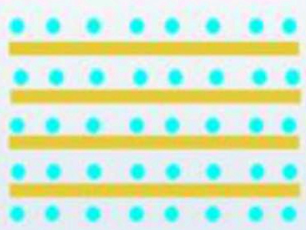



Confined Crystallization and Solvothermal Reduction

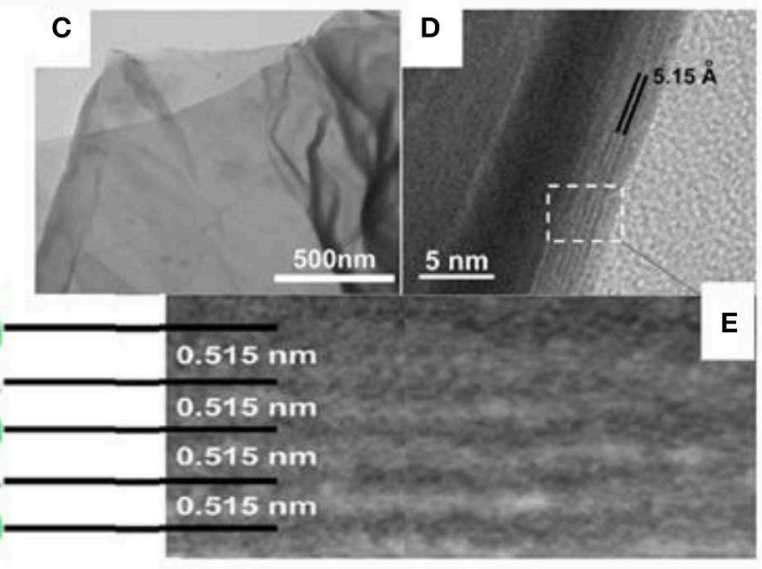

G



FIGURE 5 | (A) Schematic illustration of the layer-by-layer formation mechanism of $\beta$-Ni(OH) $2 /$ graphene nanohybrids. (B) Schematic illustration of the flexible all-solid-state thin-film supercapacitor with pseudocapacitive $\beta-\mathrm{Ni}(\mathrm{OH})_{2} /$ graphene nanohybrids as active materials. (C) TEM image of the as-prepared nanohybrids, confirming the nanosheet morphology. (D) Cross-sectional HR-TEM images and (E) enlarged view of the HR-TEM image of the curled fringe of the nanohybrid sheet. (F) Long-term cycling stability of the flexible ASSTFS based on the nanohybrids ( $98.2 \%$ for the 2,000th cycle). (G) Cycling stability of the flexible ASSTFS measured after repeated bending/extension deformation (Xie et al., 2013).

In addition to these pioneering and representative research studies, numerous reports on the integration of TMOs/TMHs with graphene to prepare high-performance electrode materials for supercapacitors have revealed the general functions of the hierarchical structures (Wang G. et al., 2012; Mahmood et al., 2019; Nguyen and Montemor, 2019). The incorporation of graphene improves the conductivity of the pseudocapacitor electrode material and the constraints of the low specific capacitance of the graphene as a double-layer capacitor electrode material, and the advantages of the two are superimposed to achieve a substantial improvement in the capacitance performance, which is a feasible strategy for improving the electrochemical performance of the TMO/TMH electrode material.

\section{TMOs/TMHs/CONDUCTING POLYMER HIERARCHICAL STRUCTURES}

Conducting polymer has become an important electrode material for pseudocapacitors due to the advantages of large capacity, good conductivity, facile synthesis, and low cost 


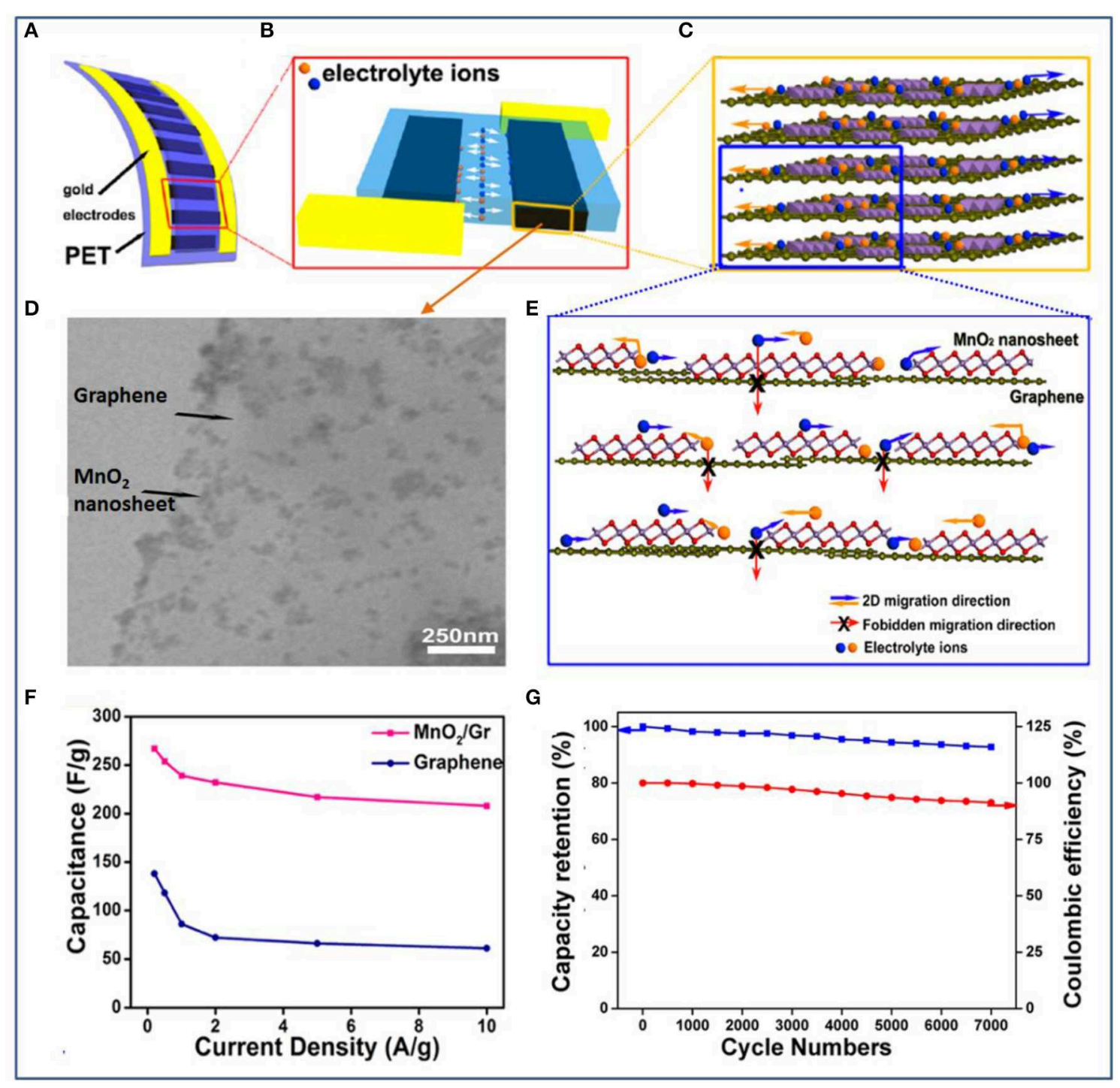

FIGURE 6 | (A) Schematic illustration of an ultraflexible planar supercapacitor constructed with a hybrid film as the working electrode, a current collector, and a gel electrolyte on a plastic polyethylene terephthalate (PET) substrate. (B) The planar supercapacitor unit, showing that the 2D hybrid thin film functions as two symmetric working electrodes. (C) The hybrid thin film was formed by stacking layers of chemically integrated quasi-2D $\delta-\mathrm{MnO}_{2}$ nanosheets and graphene sheets. (D) TEM image of the $2 \mathrm{D}$ hybrid structure with $\delta-\mathrm{MnO}_{2}$ nanosheets integrated on graphene surfaces. (E) Schematic description of the 2D planar ion transport favored within the $2 \mathrm{D} \delta-\mathrm{MnO}_{2}$ /graphene hybrid structures. (F) Comparison of specific capacitance values for the supercapacitors based on hybrids and based on graphene. (G) Capacitance retention (blue) and Coulombic efficiency (red) of the planar supercapacitor device based on hybrids over 7,000 charge/discharge cycles (Peng et al., 2013).

(Kalaji et al., 1999). In the past few years, conducting polymers have attracted increasing attention due to their great potential in supercapacitors. However, the conductive polymer-based electrode still suffers the drawbacks of low stability and poor mechanical properties, which restrict its application in fabricating supercapacitor devices (Liu et al., 2019). In terms of countermeasures, an inorganic-organic composite combination can improve the mechanical properties, electrochemical properties, and stability. Organic-inorganic composite electrode materials with excellent performance can be prepared to improve the specific capacitance and cycle stability of the electrode materials of supercapacitors.
As a representative conducting polymer, polyaniline (PANI) has frequently been used to combine with TMOs/TMHs to fabricate hierarchical structural hybrids for supercapacitor materials. As reported earlier, $\mathrm{MoO}_{3} / \mathrm{PANI}$ nanocomposites have been synthesized by a simple in-situ synthesis method using molybdenum oxide precursor precipitation and aniline monomer as raw materials, as shown in Figures 7A-C (Zheng et al., 2011). The PANI polymer chains are assembled between oxide layers, which cause the nanocomposite to exhibit a flexible layered hierarchical structure. The electrical properties of metal oxides as active supercapacitor materials are greatly improved, which gives them excellent conductivity (Figure 7D). 
A

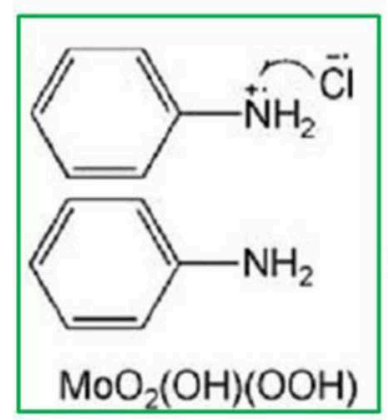

\section{In situ polymerization}
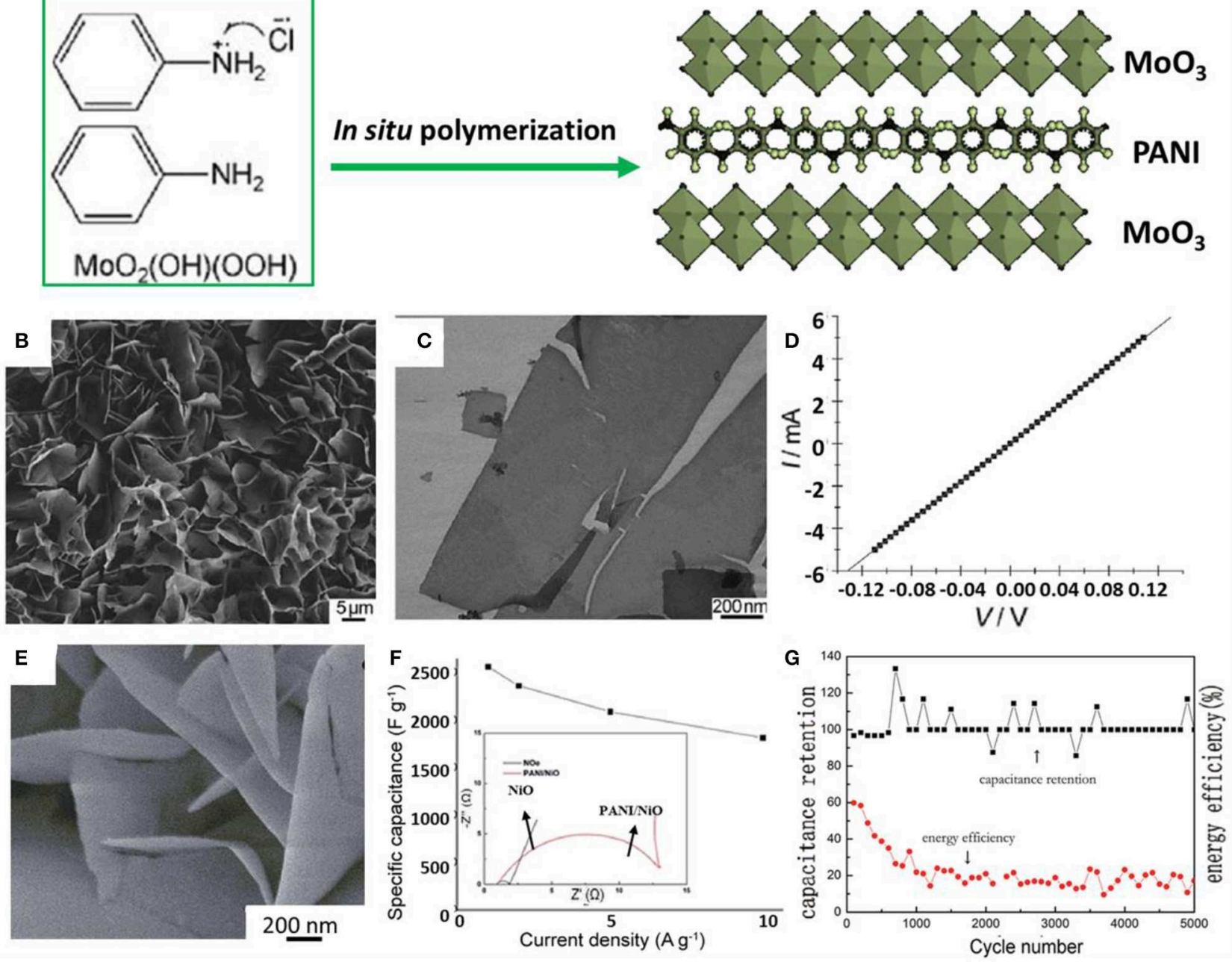

FIGURE 7 | (A) Representation of the simultaneous reaction mechanism of hybrid PANI/MoO 3 nanocomposites. (B) SEM images and (C) TEM images of the prepared hybrid PANI/MoO 3 nanosheets. (D) I-V characteristics of the hybrid nanosheet (Zheng et al., 2011). (E) SEM images of the PANI/NiO electrode. (F) Specific capacity of the PANI/NiO electrode in different current densities and (inset) EIS curves. (G) Capacitance retention and energy efficiency curves of the PANI/NiO electrode produced in the best condition (Sun et al., 2016).

The outstanding performance was inferred to derive from the robust bonding through in-situ polymerization. Hence, nanocomposites prepared by in-situ reaction at the molecular level have significantly improved specific capacity and cycle stability, making them very suitable for the electrochemical energy storage application.

A PANI-NiO composite on nickel foam that was used as a supercapacitor electrode and was fabricated via a binderfree in-situ approach showed high specific capacitance $(2,565 \mathrm{~F} / \mathrm{g}$ at a current density of $1 \mathrm{~A} / \mathrm{g})$ and excellent cycling stability (with a high retention of $100 \%$ for almost 5,000 cycles) (Sun et al., 2016). The flower-like hierarchical structures offer a structural benefit enabling high levels of redox (Figures 7E-G). Detailed studies revealed that the $\mathrm{Ni}$ foam was the current collector and $\mathrm{Ni}$ source for in-situ deposition of $\mathrm{NiO}$, establishing a steadier bonding between collector and active material. PANI that was deposited directly onto the electrode supported the structure and prevented the functional space structure from being destroyed and collapsing during the charging-discharging process. The resultant impressive cycling stability shows considerable potential for commonly used energy storage devices with long service lives.

Post-functionalization of TMOs/TMHs with PANI through polymerization provides the hybrid core-shell or sandwich hierarchical configurations. For example, adsorption of benzene amine on $\mathrm{MoO}_{3}$ nanobelts and further polymerization lead to the formation of coaxial heterostructure nanobelts of $\mathrm{MoO}_{3} / \mathrm{PANI}$, which exhibited lower electric resistance than $\mathrm{MoO}_{3}$ nanobelts and pure PANI (Figures 8A-F). The supercapacitors achieved high specific capacitances of $714 \mathrm{~F} / \mathrm{g}$ at a scan rate of $\mathrm{I} \mathrm{mV/s}$ and $632 \mathrm{~F} / \mathrm{g}$ at a current density of $1 \mathrm{~A} / \mathrm{g}$ (Jiang et al., 2014). 


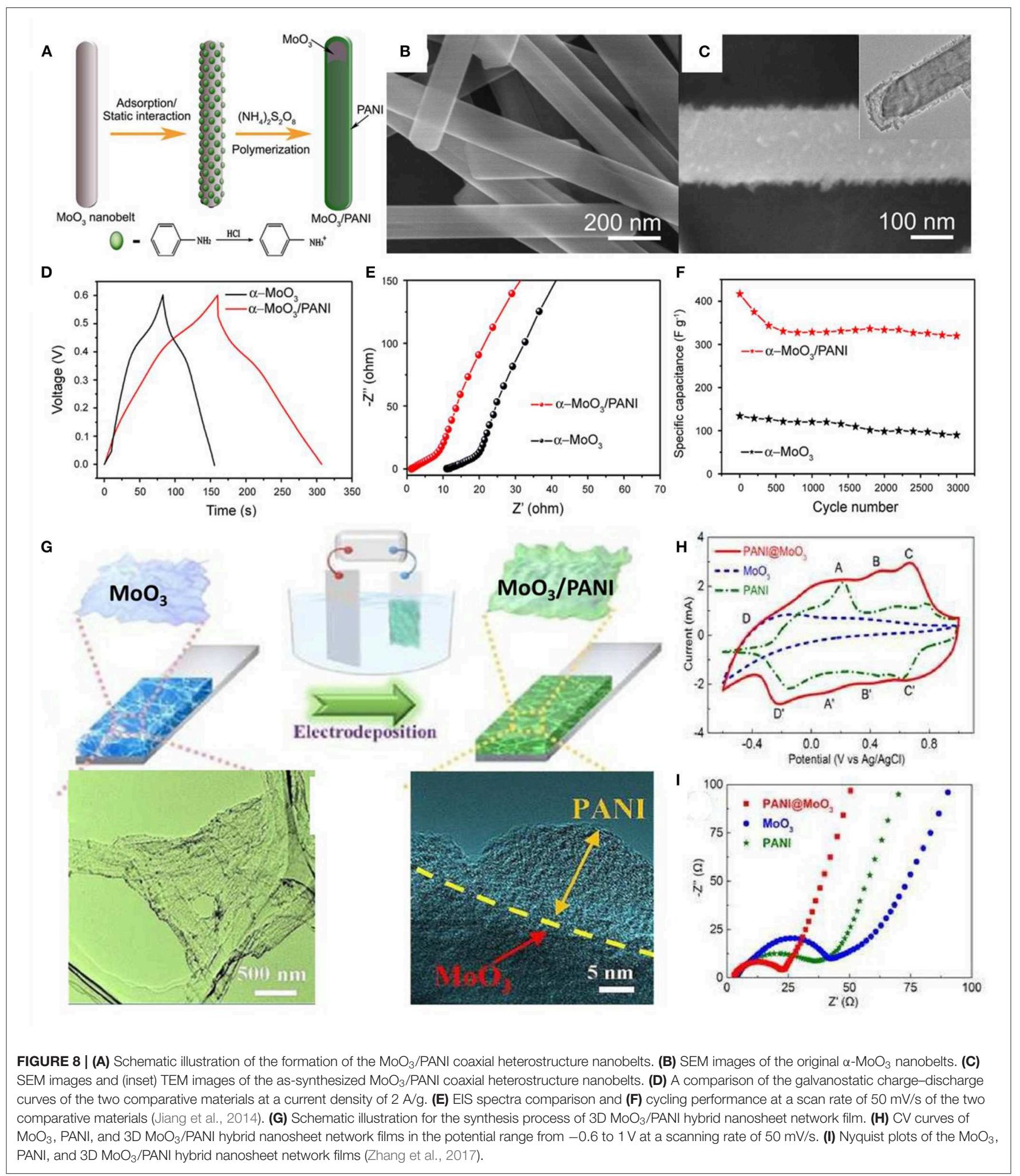

In order to overcome the low stability of conducting polymers as electrode material, a porous structure is usually introduced to guard against swelling and shrinking. In the case of a $\mathrm{MoO}_{3} /$ PANI hybrid (Zhang et al., 2017), 3D $\mathrm{MoO}_{3}$ networks are formed through a freeze-drying process, in which the ice acts as a self-sacrificial template, and the different 
nanosheets are connected by van der Waals and hydrogen bonds. The final 3D $\mathrm{MoO}_{3} / \mathrm{PANI}$ hybrid networks were achieved by further electropolymerization of PANI onto the $\mathrm{MoO}_{3}$ surface (Figure 8G). Electrochemical impedance characteristics (EIS) measurements demonstrated good electrical conductivity and ion diffusion behavior (Figures $\mathbf{8 H}, \mathbf{I}$ ). The intrinsic structural advantages and the synergetic interaction of the $3 \mathrm{D}$ networks make such a hierarchical configuration a promising structure for supercapacitor materials.

It can be seen from the above work that preparing inorganicorganic composite electrode materials by combining $2 \mathrm{D}$ TMOs/TMHs with conductive polymers can effectively improve the cycling, mechanical properties, and specific capacitance of the electrode, which can be used as an effective and feasible scheme for improving the electrochemical performance of the electrode of a supercapacitor.

\section{SUMMARY AND PERSPECTIVES}

A 2D TMOs/TMHs-based hierarchical structure combines the advantages of planar conductivity and a large specific surface area, making it an ideal candidate for the assembly of high-performance supercapacitors. To this end, finding new configurations with a hierarchical structure will guide the fabrication of supercapacitor materials with furtherimproved electrochemical performances. Besides TMOs/TMHs hierarchical structures, the integration of TMOs/TMHs with graphene or conductive polymer to form hierarchical structures has directed the recent steps forward in supercapacitor materials. In TMOs/TMHs-based hierarchical structures, graphene and conductive polymer are the key components for constructing flexible supercapacitors. By optimizing the TMOs/TMHs nanosheet orientation and stacking, electrons/ion transport channels were created, and performance was enhanced in the hierarchical energy storage devices. In summary, hierarchical structures form the prospective blueprint for fabricating highperformance supercapacitors by regulating morphologies and electronic properties.

Although great efforts have been put into supercapacitor materials in terms of the development of novel materials, synthetic technology, and structure engineering, a few problems remain at present. For instance, in TMOs/TMHs/graphene

\section{REFERENCES}

Ambade, R. B., Ambade, S. B., Shrestha, N. K., Salunkhe, R. R., Lee, W., Bagde, S. S., et al. (2017). Controlled growth of polythiophene nanofibers in $\mathrm{TiO}_{2}$ nanotube arrays for supercapacitor applications. J. Mater. Chem. A 5, 172-180. doi: 10.1039/C6TA08038C

Augustyn, V., Come, J., Lowe, M. A., Kim, J. W., Taberna, P. L., Tolbert, S. H., et al. (2013). High-rate electrochemical energy storage through $\mathrm{Li}^{+}$intercalation pseudocapacitance. Nat. Mater. 12, 518-522. doi: 10.1038/nmat3601

Bao, J., Wang, Z., Liu, W., Xu, L., Lei, F., Xie, J., et al. (2018). $\mathrm{ZnCo}_{2} \mathrm{O}_{4}$ ultrathin nanosheets towards the high performance of flexible supercapacitors and bifunctional electrocatalysis. J. Alloys Compd. 764, 565-573. doi: 10.1016/j.jallcom.2018.06.085

Bao, J., Zhang, X., Bai, L., Bai, W., Zhou, M., Xie, J., et al. (2014). All-solid-state flexible thin-film supercapacitors with high electrochemical performance based hierarchical structures, the weak interaction forces between capacitive TMOs/TMHs and graphene at the heterostructure interface have been an impediment to improving electrochemical performance. However, very recently, graphene was demonstrated to eliminate the boundary effect and enable electron behavior of the hybrid comparable with that of a single crystal without grain boundary. It is believed that this discovery may inspire fresh research into hierarchical structures using graphene as a component. Given the advantages of conductive polymer, rational design and synthesis of new types of conductive polymers with higher conductivity and stability are highly desirable, as this would pave the way for next-generation supercapacitors with superior flexibility and performance.

Besides assembling hierarchical structures for improvement of supercapacitor performance, attention could be paid to developing new 2D electroactive materials, such as the newly emerging 2D transition metal carbides/nitrides (MXenes), which possess extremely high intrinsic electronic/ionic conductivity. High intercalation capacitance $\left(\sim 1,000 \mathrm{~F} \mathrm{~cm}^{-3}\right)$ in aqueous electrolytes make these promising electrode materials for the future. Meanwhile, supercapacitor performance is also dependent on the voltage window, which is strictly limited by the electrolyte. Thus, a possible way forward is to increase the working voltage by using green electrolytes with a high electronic conductivity and voltage window, such as ionic liquid electrolytes.

\section{AUTHOR CONTRIBUTIONS}

All authors listed have made a substantial, direct and intellectual contribution to the work, and approved it for publication.

\section{FUNDING}

This work was financially supported by the National Natural Science Foundation of China for Youths (Grant Nos. 21701057, 21601067, 21905147), the Jiangsu Postdoctoral Research Foundation (Grant No. 1701109B), the China Postdoctoral Science Foundation (Grant No. 2017M611708), and the Scientific Research Startup Foundation of Jiangsu University (Grant No. 16JDG063). on a two-dimensional $\mathrm{V}_{2} \mathrm{O}_{5} \bullet \mathrm{H}_{2} \mathrm{O}$ /graphene composite. J. Mater. Chem. A 2, 10876-10881. doi: 10.1039/c3ta15293f

Brezesinski, T., Wang, J., Tolbert, S. H., and Dunn, B. (2010). Ordered mesoporous $\alpha-\mathrm{MoO}_{3}$ with iso-oriented nanocrystalline walls for thin-film pseudocapacitors. Nat. Mater. 9, 146-151. doi: 10.1038/nmat2612

Bu, Y., Sun, T., Cai, Y., Du, L., Zhuo, O., Yang, L., et al. (2017). Compressing carbon nanocages by capillarity for optimizing porous structures toward ultrahigh-volumetric-performance supercapacitors. Adv. Mater. 29:1700470. doi: 10.1002/adma.201700470

Coleman, J. N., Lotya, M., O’Neill, A., Bergin, S. D., King, P. J., Khan, U., et al. (2011). Two-dimensional nanosheets produced by liquid exfoliation of layered materials. Science 331, 568-571. doi: 10.1126/science.1194975

Cranmer, A., Baker, E., Liesiö, J., and Salo, A. (2018). A portfolio model for siting offshore wind farms with economic and environmental objectives. Eur. J. Oper. Res. 267, 304-314. doi: 10.1016/j.ejor.2017.11.026 
Dinh, T. M., Achour, A., Vizireanu, S., Dinescu, G., Nistor, L., Armstrong, K., et al. (2014). Hydrous $\mathrm{RuO}_{2}$ /carbon nanowalls hierarchical structures for allsolid-state ultrahigh-energy-density micro-supercapacitors. Nano Energy 10, 288-294. doi: 10.1016/j.nanoen.2014.10.003

Dutta, S., Pal, S., and De, S. (2019). Mixed solvent exfoliated transition metal oxides nanosheets based flexible solid state supercapacitor devices endowed with high energy density. New J. Chem 43, 12385-12395. doi: 10.1039/C9NJ03233A

Feng, X., Huang, Y., Chen, M., Chen, X., Li, C., Zhou, S., et al. (2018). Self-assembly of $3 \mathrm{D}$ hierarchical $\mathrm{MnMoO}_{4} / \mathrm{NiWO}_{4}$ microspheres for high-performance supercapacitor. J. Alloys Compd. 763, 801-807. doi: 10.1016/j.jallcom.2018.06.025

Frackowiak, E., and Beguin, F. (2001). Carbon materials for the electrochemical storage of energy in capacitors. Carbon 39, 937-950. doi: 10.1016/S0008-6223(00)00183-4

Fu, Y., Song, J., Zhu, Y., and Cao, C. (2014). High-performance supercapacitor electrode based on amorphous mesoporous $\mathrm{Ni}(\mathrm{OH})_{2}$ nanoboxes. J. Power Sources 262, 344-348. doi: 10.1016/j.jpowsour.2014.04.002

Gamby, J., Taberna, P. L., Simon, P., Fauvarque, J. F., and Chesneau, M. (2001). Studies and characterisations of various activated carbons used for carbon/carbon supercapacitors. J. Power Sources 101, 109-116. doi: 10.1016/S0378-7753(01)00707-8

Gao, H., Cao, S., and Cao, Y. (2017). Hierarchical core-shell nanosheet arrays with $\mathrm{MnO}_{2}$ grown on mesoporous $\mathrm{CoFe}_{2} \mathrm{O}_{4}$ support for highperformance asymmetric supercapacitors. Electrochim. Acta 240, 31-42. doi: 10.1016/j.electacta.2017.04.062

Gao, S., Sun, Y., Lei, F., Liang, L., Liu, J., Bi, W., et al. (2014). Ultrahigh energy density realized by a single-layer $\beta$-Co $(\mathrm{OH})_{2}$ all-solid-state asymmetric supercapacitor. Angew. Chem. Int. Ed. 53, 12789-12793. doi: 10.1002/anie.201407836

Gong, X., Liu, G., Li, Y., and Teoh, W. Y. (2016). Functionalizedgraphene composites: fabrication and applications in sustainable energy and environment. Chem. Mater. 28, 8082-8118. doi: 10.1021/acs.chemmater.6b01447

González, A., Goikolea, E., Barrena, J. A., and Mysyk, R. (2016). Review on supercapacitors: technologies and materials. Renew. Sust. Energ. Rev. 58, 1189-1206. doi: 10.1016/j.rser.2015.12.249

Hanlon, D., Backes, C., Higgins, T. M., Hughes, M., O’Neill, A., King, P., et al. (2014). Production of molybdenum trioxide nanosheets by liquid exfoliation and their application in high-performance supercapacitors. Chem. Mater. 26, 1751-1763. doi: $10.1021 / \mathrm{cm} 500271 \mathrm{u}$

Ho, K. C., and Lin, L. Y. (2019). A review of electrode materials based on coreshell nanostructures for electrochemical supercapacitors. J. Mater. Chem. A 7, 3516-3530. doi: 10.1039/C8TA11599K

Hu, Z., Xiao, X., Jin, H., Li, T., Chen, M., Liang, Z., et al. (2017). Rapid mass production of two-dimensional metal oxides and hydroxides via the molten salts method. Nat. Commun. 8, 1-9. doi: 10.1038/ncomms15630

Huang, M., Zhang, Y., Li, F., Zhang, L., Ruoff, R. S., Wen, Z., et al. (2014). Self-assembly of mesoporous nanotubes assembled from interwoven ultrathin birnessite-type $\mathrm{MnO}_{2}$ nanosheets for asymmetric supercapacitors. Sci. Rep. 4:3878. doi: $10.1038 /$ srep03878

Huang, Y., Tao, J., Meng, W., Zhu, M., Huang, Y., Fu, Y., et al. (2015). Superhigh rate stretchable polypyrrole-based supercapacitors with excellent cycling stability. Nano Energy 11, 518-525. doi: 10.1016/j.nanoen.2014.10.031

Huang, Z. H., Song, Y., Feng, D. Y., Sun, Z., Sun, X., and Liu, X. X. (2018). High mass loading $\mathrm{MnO}_{2}$ with hierarchical nanostructures for supercapacitors. ACS Nano 12, 3557-3567. doi: 10.1021/acsnano.8b00621

Ida, S., Shiga, D., Koinuma, M., and Matsumoto, Y. (2008). Synthesis of hexagonal nickel hydroxide nanosheets by exfoliation of layered nickel hydroxide intercalated with dodecyl sulfate ions. J. Am. Chem. Soc. 130, 14038-14039. doi: $10.1021 /$ ja804397n

Ji, X., Hallam, P. M., Houssein, S. M., Kadara, R., Lang, L., and Banks, C. E. (2012). Printable thin film supercapacitors utilizing single crystal cobalt hydroxide nanosheets. RSC Adv. 2, 1508-1515. doi: 10.1039/C1RA01061A

Jiang, F., Li, W., Zou, R., Liu, Q., Xu, K., An, L., et al. (2014). $\mathrm{MoO}_{3} / \mathrm{PANI}$ coaxial heterostructure nanobelts by in situ polymerization for high performance supercapacitors. Nano Energy 7, 72-79. doi: 10.1016/j.nanoen.2014.04.007

Jiang, J., Li, Y., Liu, J., Huang, X., Yuan, C., and Lou, X. W. (2012). Recent advances in metal oxide-based electrode architecture design for electrochemical energy storage. Adv. Mater. 24, 5166-5180. doi: 10.1002/adma.2012 02146

Jin, Y., Tian, K., Wei, L., Zhang, X., and Guo, X. (2016). Hierarchical porous microspheres of activated carbon with a high surface area from spores for electrochemical double-layer capacitors. J. Mater. Chem. A 4, 15968-15979. doi: 10.1039/C6TA05872H

Kalaji, M., Murphy, P. J., and Williams, G. O. (1999). The study of conducting polymers for use as redox supercapacitors. Synth. Met. 102, 1360-1361. doi: 10.1016/S0379-6779(98)01334-4

Kate, R. S., Khalate, S. A., and Deokate, R. J. (2018). Overview of nanostructured metal oxides and pure nickel oxide $(\mathrm{NiO})$ electrodes for supercapacitors: a review. J. Alloys Compd. 734, 89-111. doi: 10.1016/j.jallcom.2017.10.262

Kumbhar, V. S., and Kim, D. H. (2018). Hierarchical coating of $\mathrm{MnO}_{2}$ nanosheets on $\mathrm{ZnCo}_{2} \mathrm{O}_{4}$ nanoflakes for enhanced electrochemical performance of asymmetric supercapacitors. Electrochim. Acta 271, 284-296. doi: 10.1016/j.electacta.2018.03.147

Lee, H., Cho, M. S., Kim, I. H., Nam, J. D., and Lee, Y. (2010). $\mathrm{RuO}_{\mathrm{x}} /$ polypyrrole nanocomposite electrode for electrochemical capacitors. Synth. Met. 160, 1055-1059. doi: 10.1016/j.synthmet.2010.02.026

Lee, W. J., and Sung, Y. M. (2012). Synthesis of anatase nanosheets with exposed (001) facets via chemical vapor deposition. Cryst. Growth Des. 12, 5792-5795. doi: $10.1021 / \mathrm{cg} 301317 \mathrm{j}$

Li, Z., Hu, Z., Peng, J., Wu, C., Yang, Y., Feng, F., et al. (2014). Ultrahigh infrared photoresponse from core-shell single-domain- $\mathrm{VO}_{2} / \mathrm{V}_{2} \mathrm{O}_{5}$ heterostructure in nanobeam. Adv. Funct. Mater. 24, 1821-1830. doi: 10.1002/adfm.201302967

Lim, Y., Yoon, J., Yun, J., Kim, D., Hong, S. Y., Lee, S. J., et al. (2015). Correction to biaxially stretchable, integrated array of high performance microsupercapacitors. ACS Nano 9, 6634-6634. doi: 10.1021/acsnano.5b02991

Liu, C., Yu, Z., Neff, D., Zhamu, A., and Jang, B. Z. (2010). Graphene-based supercapacitor with an ultrahigh energy density. Nano Lett. 10, 4863-4868. doi: $10.1021 / \mathrm{nl} 102661 \mathrm{q}$

Liu, J., Zhang, L., Wu, H. B., Lin, J., Shen, Z., and Lou, X. W. D. (2014). Highperformance flexible asymmetric supercapacitors based on a new graphene foam/carbon nanotube hybrid film. Energy Environ. Sci. 7, 3709-3719. doi: 10.1039/C4EE01475H

Liu, J., Zhong, M., Li, J., Pan, A., and Zhu, X. (2015). Few-layer $\mathrm{WO}_{3}$ nanosheets for high-performance UV-photodetectors. Mater. Lett. 148, 184-187. doi: 10.1016/j.matlet.2015.02.088

Liu, L., Yao, T., Tan, X., Liu, Q., Wang, Z., Shen, D., et al. (2012). Room temperature intercalation-deintercalation strategy towards $\mathrm{VO}_{2}$ (B) single layers with atomic thickness. Small 8, 3752-3756. doi: 10.1002/smll.2012 01552

Liu, P., Yan, J., Guang, Z., Huang, Y., Li, X., Huang, W., et al. (2019). Recent advancements of polyaniline-based nanocomposites for supercapacitors. J. Power Sources 424, 108-130. doi: 10.1016/j.jpowsour.2019.03.094

Liu, R., Cho, S. I., and Lee, S. B. (2008). Poly(3, 4-ethylenedioxythiophene) nanotubes as electrode materials for a high-powered supercapacitor. Nanotechnology 19:215710. doi: 10.1088/0957-4484/19/21/215710

Liu, W., Wang, Z., Su, Y., Li, Q., Zhao, Z., and Geng, F. (2017). Molecularly stacking manganese dioxide/titanium carbide sheets to produce highly flexible and conductive film electrodes with improved pseudocapacitive performances. Adv. Energy Mater. 7:1602834. doi: 10.1002/aenm.201602834

Liu, Y., Liang, L., Xiao, C., Hua, X., Li, Z., Pan, B., et al. (2016). Promoting photogenerated holes utilization in pore-rich $\mathrm{WO}_{3}$ ultrathin nanosheets for efficient oxygen-evolving photoanode. Adv. Energy Mater. 6:1600437. doi: 10.1002/aenm.201600437

Liu, Y., Zhou, T., Zheng, Y., He, Z., Xiao, C., Pang, W. K., et al. (2017). Local electric field facilitates high-performance Li-ion batteries. ACS Nano 11, 8519-8526. doi: 10.1021/acsnano.7b04617

Lukatskaya, M. R., Dunn, B., and Gogotsi, Y. (2016). Multidimensional materials and device architectures for future hybrid energy storage. Nat. Commun. 7, 1-13. doi: 10.1038/ncomms12647

Lyu, W., Yu, M., Feng, J., and Yan, W. (2019). Facile synthesis of corallike hierarchical polyaniline micro/nanostructures with enhanced supercapacitance and adsorption performance. Polymer 162, 130-138. doi: 10.1016/j.polymer.2018.12.037

Mahmood, N., De Castro, I. A., Pramoda, K., Khoshmanesh, K., Bhargava, S. K. and Kalantar-Zadeh, K. (2019). Atomically thin two-dimensional metal oxide 
nanosheets and their heterostructures for energy storage. Energy Storage Mater. 16, 455-480. doi: 10.1016/j.ensm.2018.10.013

Mei, J., Liao, T., and Sun, Z. (2018). Two-dimensional metal oxide nanosheets for rechargeable batteries. J. Energy Chem. 27, 117-127. doi: 10.1016/j.jechem.2017.10.012

Mo, Z., Xu, H., Chen, Z., She, X., Song, Y., Wu, J., et al. (2018). Selfassembled synthesis of defect-engineered graphitic carbon nitride nanotubes for efficient conversion of solar energy. Appl. Catal. B Environ. 225, 154-161. doi: 10.1016/j.apcatb.2017.11.041

Muzaffar, A., Ahamed, M. B., Deshmukh, K., and Thirumalai, J. (2019). A review on recent advances in hybrid supercapacitors: design, fabrication and applications. Renew. Sust. Energ. Rev. 101, 123-145. doi: 10.1016/j.rser.2018.10.026

Najafpour, M. M., Hołynska, M., and Salimi, S. (2015). Applications of the "nano to bulk" Mn oxides: Mn oxide as a Swiss army knife. Coordin. Chem. Rev. 285, 65-75. doi: 10.1016/j.ccr.2014.11.001

Nguyen, T., and Montemor, M. D. F. (2019). Metal oxide and hydroxidebased aqueous supercapacitors: from charge storage mechanisms and functional electrode engineering to need-tailored devices. Adv. Sci. 6:1801797. doi: 10.1002/advs.201801797

Novoselov, K. S., Fal, V. I., Colombo, L., Gellert, P. R., Schwab, M. G., and Kim, K. (2012). A roadmap for graphene. Nature 490, 192-200. doi: $10.1038 /$ nature 11458

Ouyang, Y., Huang, R., Xia, X., Ye, H., Jiao, X., Wang, L., et al. (2019). Hierarchical structure electrodes of $\mathrm{NiO}$ ultrathin nanosheets anchored to $\mathrm{NiCo}_{2} \mathrm{O}_{4}$ on carbon cloth with excellent cycle stability for asymmetric supercapacitors. Chem. Eng. J. 355, 416-427. doi: 10.1016/j.cej.2018.08.142

Peng, L., Peng, X., Liu, B., Wu, C., Xie, Y., and Yu, G. (2013). Ultrathin two-dimensional $\mathrm{MnO}_{2}$ /graphene hybrid nanostructures for highperformance, flexible planar supercapacitors. Nano Lett. 13, 2151-2157. doi: $10.1021 / \mathrm{nl} 400600 \mathrm{x}$

Peng, X., Guo, Y., Yin, Q., Wu, J., Zhao, J., Wang, C., et al. (2017). Doubleexchange effect in two-dimensional $\mathrm{MnO}_{2}$ nanomaterials. J. Am. Chem. Soc. 139, 5242-5248. doi: 10.1021/jacs.7b01903

Qi, R., Nie, J., Liu, M., Xia, M., and Lu, X. (2018). Stretchable $\mathrm{V}_{2} \mathrm{O}_{5} /$ PEDOT supercapacitors: a modular fabrication process and charging with triboelectric nanogenerators. Nanoscale 10, 7719-7725. doi: 10.1039/C8NR00444G

Rui, X., Lu, Z., Yu, H., Yang, D., Hng, H. H., Lim, T. M., et al. (2013). Ultrathin $\mathrm{V}_{2} \mathrm{O}_{5}$ nanosheet cathodes: realizing ultrafast reversible lithium storage. Nanoscale 5, 556-560. doi: 10.1039/C2NR33422D

Salanne, M., Rotenberg, B., Naoi, K., Kaneko, K., Taberna, P. L., Grey, C. P., et al. (2016). Efficient storage mechanisms for building better supercapacitors. Nat. Energy 1, 1-10. doi: 10.1038/nenergy.2016.70

Shang, Y., Wang, C., He, X., Li, J., Peng, Q., Shi, E., et al. (2015). Self-stretchable, helical carbon nanotube yarn supercapacitors with stable performance under extreme deformation conditions. Nano Energy 12, 401-409. doi: 10.1016/j.nanoen.2014.11.048

Simon, P., and Gogotsi, Y. (2010). "Materials for electrochemical capacitors," in Nanoscience and Technology, 320-329. doi: 10.1142/9789814287005_0033

Snook, G. A., Kao, P., and Best, A. S. (2011). Conducting-polymer-based supercapacitor devices and electrodes. J. Power Sources 196, 1-12. doi: 10.1016/j.jpowsour.2010.06.084

Song, M. S., Lee, K. M., Lee, Y. R., Kim, I. Y., Kim, T. W., Gunjakar, J. L., et al. (2010). Porously assembled 2D nanosheets of alkali metal manganese oxides with highly reversible pseudocapacitance behaviors. J. Phy. Chem. C 114, 22134-22140. doi: 10.1021/jp108969s

Song, X., Shi, Y., Li, G., Shen, Z., Hu, X., Lyu, Z., et al. (2018). Numerical analysis of the heat production performance of a closed loop geothermal system. Renew Energy 120, 365-378. doi: 10.1016/j.renene.2017.12.065

Staaf, L. G. H., Lundgren, P., and Enoksson, P. (2014). Present and future supercapacitor carbon electrode materials for improved energy storage used in intelligent wireless sensor systems. Nano Energy 9, 128-141. doi: 10.1016/j.nanoen.2014.06.028

Stankovich, S., Dikin, D. A., Dommett, G. H., Kohlhaas, K. M., Zimney, E. J., Stach, E. A., et al. (2006). Graphene-based composite materials. Nature 442, 282-286. doi: 10.1038/nature04969

Sugimoto, W., Iwata, H., Yasunaga, Y., Murakami, Y., and Takasu, Y. (2003). Preparation of ruthenic acid nanosheets and utilization of its interlayer surface for electrochemical energy storage. Angew. Chem. Int. Ed. 42, 4092-4096. doi: 10.1002/anie.200351691

Sun, B., He, X., Leng, X., Yang, J., Zhao, Y., Suo, H., et al. (2016). Flowerlike polyaniline-NiO structures: a high specific capacity supercapacitor electrode material with remarkable cycling stability. RSC Adv. 6, 43959-43963. doi: 10.1039/C6RA02534J

Sun, J., Li, W., Zhang, B., Li, G., Jiang, L., Chen, Z., et al. (2014). 3D core/shell hierarchies of $\mathrm{MnOOH}$ ultrathin nanosheets grown on $\mathrm{NiO}$ nanosheet arrays for high-performance supercapacitors. Nano Energy 4, 56-64. doi: 10.1016/j.nanoen.2013.12.006

Sun, Z., Liao, T., Dou, Y., Hwang, S. M., Park, M. S., Jiang, L., et al. (2014). Generalized self-assembly of scalable two-dimensional transition metal oxide nanosheets. Nat. Commun. 5, 1-9. doi: 10.1038/ncomms4813

Sun, Z., Liao, T., and Kou, L. (2017). Strategies for designing metal oxide nanostructures. Sci. China Mater. 60, 1-24. doi: 10.1007/s40843-016-5117-0

Tao, P., Yao, S., Liu, F., Wang, B., Huang, F., and Wang, M. (2019). Recent advances in exfoliation techniques of layered and non-layered materials for energy conversion and storage. J. Mater. Chem. A 7, 23512-23536. doi: 10.1039/C9TA06461C

Wang, C., Du, G., Stahl, K., Huang, H., Zhong, Y., and Jiang, J. Z. (2012). Ultrathin $\mathrm{SnO}_{2}$ nanosheets: oriented attachment mechanism, nonstoichiometric defects, and enhanced lithium-ion battery performances. J. Phys. Chem. C. 116, 40004011. doi: 10.1021/jp300136p

Wang, F., Wu, X., Yuan, X., Liu, Z., Zhang, Y., Fu, L., et al. (2017). Latest advances in supercapacitors: from new electrode materials to novel device designs. Chem. Soc. Rev. 46, 6816-6854. doi: 10.1039/C7CS00205J

Wang, G., Zhang, L., and Zhang, J. (2012). A review of electrode materials for electrochemical supercapacitors. Chem. Soc. Rev. 41, 797-828. doi: 10.1039/C1CS15060J

Wang, Y., Guo, J., Wang, T., Shao, J., Wang, D., and Yang, Y. W. (2015). Mesoporous transition metal oxides for supercapacitors. Nanomater 5 , 1667-1689. doi: 10.3390/nano5041667

Wen, P., Ai, L., Liu, T., Hu, D., and Yao, F. (2017). Hydrothermal topological synthesis and photocatalyst performance of orthorhombic $\mathrm{Nb}_{2} \mathrm{O}_{5}$ rectangle nanosheet crystals with dominantly exposed (010) facet. Mater. Des. 117, 346-352. doi: 10.1016/j.matdes.2017.01.004

Wen, S., Liu, Y., Zhu, F., Shao, R., and Xu, W. (2018). Hierarchical $\mathrm{MoS}_{2}$ nanowires/ $\mathrm{NiCo}_{2} \mathrm{O}_{4}$ nanosheets supported on $\mathrm{Ni}$ foam for highperformance asymmetric supercapacitors. Appl. Surf. Sci. 428, 616-622. doi: 10.1016/j.apsusc.2017.09.189

Wu, H. B., Pang, H., and Lou, X. W. D. (2013). Facile synthesis of mesoporous $\mathrm{Ni}_{0.3} \mathrm{Co}_{2.7} \mathrm{O}_{4}$ hierarchical structures for high-performance supercapacitors. Energy Environ. Sci. 6, 3619-3626. doi: 10.1039/c3ee42101e

Xie, J., Sun, X., Zhang, N., Xu, K., Zhou, M., and Xie, Y. (2013). Layer-by-layer $\beta$-Ni $(\mathrm{OH})_{2}$ /graphene nanohybrids for ultraflexible all-solid-state thin-film supercapacitors with high electrochemical performance. Nano Energy 2, 65-74. doi: 10.1016/j.nanoen.2012.07.016

Xu, Q., Lv, Y., Dong, C., Sreeprased, T. S., Tian, A., Zhang, H., et al. (2015). Three-dimensional micro/nanoscale architectures: fabrication and applications. Nanoscale 7, 10883-10895. doi: 10.1039/C5NR 02048D

Yang, J., Zeng, Z., Kang, J., Betzler, S., Czarnik, C., Zhang, X., et al. (2019). Formation of two-dimensional transition metal oxide nanosheets with nanoparticles as intermediates. Nat. Mater. 18, 970-976. doi: 10.1038/s41563-019-0415-3

Yu, M., Qiu, W., Wang, F., Zhai, T., Fang, P., Lu, X., et al. (2015). Three dimensional architectures: design, assembly and application in electrochemical capacitors. J. Mater. Chem. A 3, 15792-15823. doi: 10.1039/C5TA02743H

Yu, T., Lim, B., and Xia, Y. (2010). Aqueous-phase synthesis of single-crystal ceria nanosheets. Angew. Chem. Int. Ed. 49, 4484-4487. doi: 10.1002/anie.201001521

Yuan, C., Wu, H. B., Xie, Y., and Lou, X. W. (2014). Mixed transition-metal oxides: design, synthesis, and energy-related applications. Angew. Chem. Int. Ed. 53, 1488-1504. doi: 10.1002/anie.201303971

Yue, Y., and Liang, H. (2015). Hierarchical micro-architectures of electrodes for energy storage. J. Power Sources 284, 435-445. doi: 10.1016/j.jpowsour.2015.03.069

Yuksel, Y. E., and Ozturk, M. (2017). Thermodynamic and thermoeconomic analyses of a geothermal energy based integrated system for 
hydrogen production. Int. J. Hydrog. Energ. 42, 2530-2546. doi: 10.1016/j.ijhydene.2016.04.172

Zavabeti, A., Ou, J. Z., Carey, B. J., Syed, N., Orrell-Trigg, R., Mayes, E. L., et al. (2017). A liquid metal reaction environment for the room-temperature synthesis of atomically thin metal oxides. Science 358, 332-335. doi: 10.1126/science.aao4249

Zhang, H., Gao, L., and Gong, Y. (2015). Exfoliated $\mathrm{MoO}_{3}$ nanosheets for high-capacity lithium storage. Electrochem. Commun. 52, 67-70. doi: 10.1016/j.elecom.2015.01.014

Zhang, K., Wang, Y., Ma, X., Zhang, H., Hou, S., Zhao, J., et al. (2017). Three dimensional molybdenum oxide/polyaniline hybrid nanosheet networks with outstanding optical and electrochemical properties. New J. Chem. 41, 10872-10879. doi: 10.1039/C7NJ02151H

Zhang, N., Chu, J., Li, C., Chen, H., and Li, Q. (2010). A facile route to synthesize the $\mathrm{Ti}_{5} \mathrm{NbO}_{14}$ nanosheets by mechanical cleavage process J. Am. Ceram. Soc. 93, 536-540. doi: 10.1111/j.1551-2916.2009.03405.x

Zhang, Y. Z., Wang, Y., Cheng, T., Lai, W. Y., Pang, H., and Huang, W. (2015). Flexible supercapacitors based on paper substrates: a new paradigm for low-cost energy storage. Chem. Soc. Rev. 44, 5181-5199. doi: 10.1039/C5CS00174A

Zhao, G., Li, J., Jiang, L., Dong, H., Wang, X., and Hu, W. (2012). Synthesizing $\mathrm{MnO}_{2}$ nanosheets from graphene oxide templates for high performance pseudosupercapacitors. Chem. Sci. 3, 433-437. doi: 10.1039/ C1SC00722J

Zhao, Y., and Sun, X. (2018). Molecular layer deposition for energy conversion and storage. ACS Energy Lett. 3, 899-914. doi: 10.1021/acsenergylett.8b00145

Zheng, L., Xu, Y., Jin, D., and Xie, Y. (2011). Polyaniline-intercalated molybdenum oxide nanocomposites: simultaneous synthesis and their enhanced application for supercapacitor. Chem. Asian J. 6, 1505-1514. doi: 10.1002/asia.201000770

Zheng, M., Xiao, X., Li, L., Gu, P., Dai, X., Tang, H., et al. (2018). Hierarchically nanostructured transition metal oxides for supercapacitors. Sci. China Mater. 61, 185-209. doi: 10.1007/s40843-017-9095-4
Zheng, X., Ye, Y., Yang, Q., Geng, B., and Zhang, X. (2016). Hierarchical structures composed of $\mathrm{MnCo}_{2} \mathrm{O}_{4} @ \mathrm{MnO}_{2}$ core-shell nanowire arrays with enhanced supercapacitor properties. Dalton Trans. 45, 572-578. doi: $10.1039 / \mathrm{C} 5 \mathrm{DT} 03780 \mathrm{H}$

Zhu, G., Xi, C., Xu, H., Zheng, D., Liu, Y., Xu, X., et al. (2012). Hierarchical NiO hollow microspheres assembled from nanosheet-stacked nanoparticles and their application in a gas sensor. RSC Adv. 2, 4236-4241. doi: $10.1039 / \mathrm{c} 2 \mathrm{ra01307j}$

Zhu, J., Cao, L., Wu, Y., Gong, Y., Liu, Z., Hoster, H. E., et al. (2013). Building 3D structures of vanadium pentoxide nanosheets and application as electrodes in supercapacitors. Nano Lett. 13, 5408-5413. doi: 10.1021/nl402969r

Zhu, S., Li, L., Liu, J., Wang, H., Wang, T., Zhang, Y., et al. (2018). Structural directed growth of ultrathin parallel birnessite on $\beta-\mathrm{MnO}_{2}$ for high-performance asymmetric supercapacitors. ACS Nano 12, 1033-1042. doi: $10.1021 /$ acsnano.7b03431

Zhu, Y., Cao, C., Tao, S., Chu, W., Wu, Z., and Li, Y. (2014). Ultrathin nickel hydroxide and oxide nanosheets: synthesis, characterizations and excellent supercapacitor performances. Sci. Rep. 4:5787. doi: 10.1038/srep 05787

Conflict of Interest: The authors declare that the research was conducted in the absence of any commercial or financial relationships that could be construed as a potential conflict of interest.

Copyright $\odot 2020$ Guan, Wang, Zhang, Bao, Gong and Liu. This is an open-access article distributed under the terms of the Creative Commons Attribution License (CC $B Y)$. The use, distribution or reproduction in other forums is permitted, provided the original author(s) and the copyright owner(s) are credited and that the original publication in this journal is cited, in accordance with accepted academic practice. No use, distribution or reproduction is permitted which does not comply with these terms. 